\title{
ALLERGIC REACTION TO ESCHERICHIA COLI-ASPARAGINASE IN CHILDHOOD ACUTE LYMPHOBLASTIC LEUKEMIA: A STUDY IN A TERTIARY HOSPITAL IN INDONESIA
}

\author{
NUR MELANI SARI ${ }^{1}$, NABILLA PUTRI OSSEVA ${ }^{2}$, NUR SURYAWAN ${ }^{1}$ \\ ${ }^{1}$ Department of Pediatrics, Division of Hematology and Oncology, Faculty of Medicine, Universitas Padjadjaran-Dr. Hasan Sadikin Hospital, \\ Bandung, Indonesia. ${ }^{2}$ Faculty of Medicine, Universitas Padjadjaran, Bandung, Indonesia. Email: nur.melani.sari@unpad.ac.id
}

Received: 02 January 2019, Revised and Accepted: 24 February 2020

\section{ABSTRACT}

Objective: The objective of the study was to determine and describe the characteristics of allergic reactions to Escherichia coli-Asparaginase (E. coli-ASP).

Methods: This cross-sectional study was performed at Hasan Sadikin Bandung General Hospital on acute lymphoblastic leukemia patients diagnosed from January 1, 2018, to August 31, 2019, confirmed by bone marrow examination. Data were extracted from Bandung Online Pediatric Cancer Registry, medical records, protocol therapy documents, and interview with patient's guardian.

Results: Out of 68 patients, 26 patients (37.6\%) were allergic to E. coli-ASP. Twenty-two patients with recorded manifestation's data evoked 35 symptoms and graded according to common terminology criteria for adverse event v3.0., fever, and urticaria are the most frequent manifestation. While Grade 2 and Grade 3 are the most often developed allergic reaction, patients with age range from 1 to 14 years, male and high risk is mainly allergic.

Conclusion: Allergic rate to E. coli-ASP at Hasan Sadikin General Hospital is 37.6\%. The most frequent manifestation is fever and urticaria (20\%, respectively), Grades 2 and 3 (32\%, respectively), and emerged mostly after administration of fourth dose E. coli-ASP (26.9\%). Despite the characteristic differences between allergic and non-allergic group, it is not statistically significant.

Keywords: Acute lymphoblastic leukemia, Allergic reaction, Clinical manifestation, Escherichia coli-Asparaginase, Pediatric.

(C) 2020 The Authors. Published by Innovare Academic Sciences Pvt Ltd. This is an open access article under the CC BY license (http://creativecommons. org/licenses/by/4. 0/) DOI: http://dx.doi.org/10.22159/ajpcr.2020.v13i4.36807

\section{INTRODUCTION}

Acute lymphoblastic leukemia (ALL) accounts as the most common childhood cancer in the world [1]. Since 1948, a therapeutic scheme to treat ALL has been evolved to create ideal and effective treatment [2]. Globally, the survival rate has surpassed $80 \%$ [3]. In low-middle income countries, the survival rate is relatively far below the global average $(<35 \%)[3,4]$. In Dr. Hasan Sadikin General Hospital, the survival rate shows unsatisfactory in number (only $9.5 \%$ ) with a death rate of $27.8 \%[5]$

Different modalities of cancer treatment include radiation, surgery, chemotherapy, hormonal therapy, immunotherapy, biologic therapy, and cryosurgery were used for cancer treatment [6,7]. L-asparaginase (L-Asp) is one essential component in the chemotherapy regimen used to treat ALL in the induction phase [7,8]. L-Asp is extracted from bacterial component to hydrolyzes asparagine, an amino acid essential for blasts functioning [9]. To date, there have been three formulations available in the world, Escherichia coli-Asparaginase (E. coli-ASP), a pegylated form of E. coli-ASP (PEG-Asp), and Crisantaspase (Erwinase). In Indonesia, E. coli-ASP is the only available formulation nevertheless in the past decades have shown a rapid development of cancer therapy to stop the growth and metastasis of the tumor $[8,10,11]$.

Over the years, L-Asp has been related to drug toxicities, such as pancreatitis, liver dysfunction, hyperammonemia, and hypersensitivity reactions [12]. The incidence of patients who developed an allergic reaction to E. coli-Asp ranges from 10 to $36 \%$ in America and Poland [13-15]. The allergic reaction varies from mild reactions to severe systematic reactions such as anaphylaxis [16]. A study stated that in 410 patients who received E. coli-ASP therapy, $41 \%$ of them developed clinical manifestation of allergic reaction [17]. These reactions result in the suboptimal treatment outcomes regarding the formation of antibodies to neutralize the medication $[17,18]$. Consecutively, it increases the morbidity and mortality-related treatment rate and worsens the outcome $[4,19]$.

Studies about the allergic reaction and the clinical manifestation of the immune response to E. coli-ASP in Indonesia are not yet available. This study aimed to investigate the incident rate and to describe the events of an allergic reaction to E. coli-ASP of children with ALL enrolled in two protocols applied in Indonesia.

\section{METHODS}

This study conducted with a retrospective approach of children aged 0-18 years diagnosed with ALL in Hasan Sadikin General Hospital and had received E. coli-ASP (Leunase ${ }^{\circledR}$ ) therapy. The subject number of the study was determined by the total sampling method. A thorough investigation was done through the patient's medical record through ICD code C90.0 for ALL, data from Bandung Online Pediatric Cancer Registry, protocol therapy documents from the hospital pharmacy and phone call interview with the patient's guardian. Pediatric patients diagnosed with LLA during January 2018-August 2019 and had received at least one dose of E. coli-ASP (Leunase $($ ) therapy were included in the study. ALL diagnosis was established by morphological analysis of bone marrow puncture aspirate.

In this period, 138 patients were listed, as shown in Fig. 1. Investigation through treatment protocol documents revealed that 69 patients had not received Leunase ${ }^{\circledR}$ to some conditions. Abandoned treatment was defined as a patient who had not received any cure-directed therapy for 4 or more weeks. Interrupted treatment included missed treatment, lost to follow-up (absence of treatment $<4$ weeks), specific treatment 

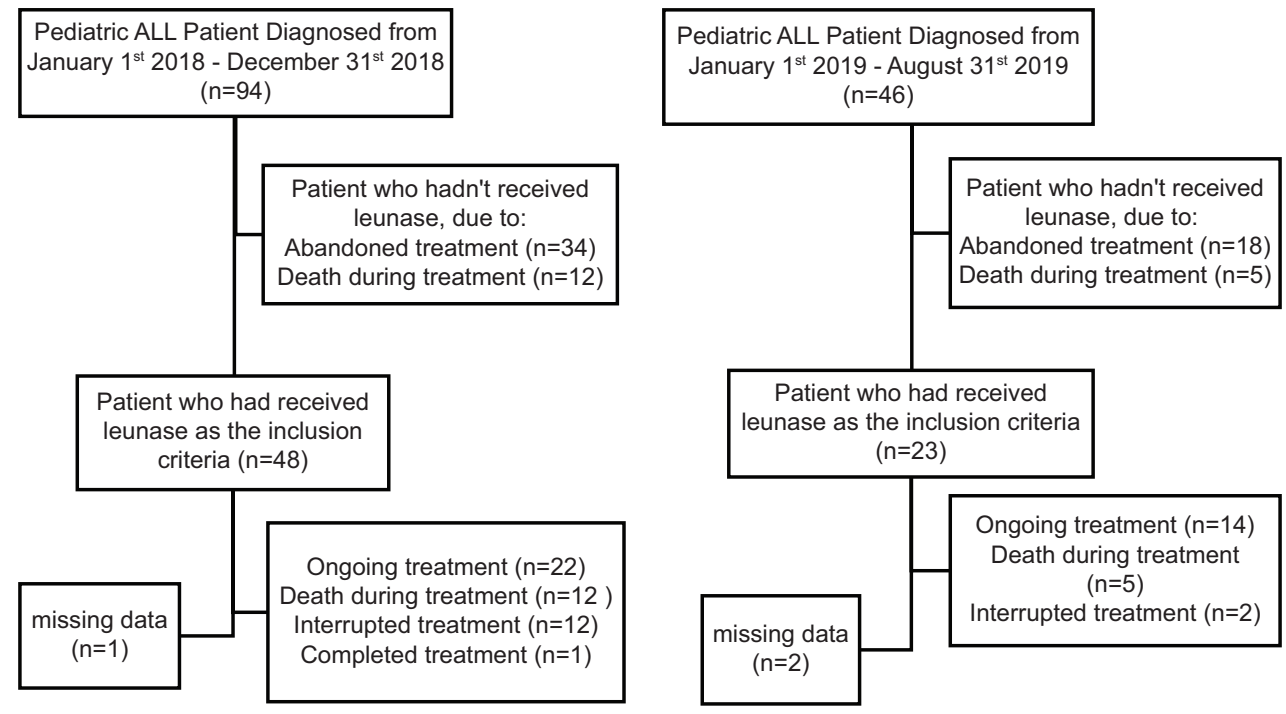

Fig. 1: Flow diagram study of selection process

refusal in specified time and discontinuation of therapy. Meanwhile, a death during therapy defined as a patient who died during treatment due to the effect of disease, infection, or chemotherapy toxicities [2].

A total of 71 patients had received Leunase ${ }^{\circledR}$ treatment during the induction phase, but three were excluded due to missing data. Twentyone patients who were diagnosed in 2019 underwent therapy, according to the 2018 Indonesian protocol therapy of ALL, and 47 patients who were diagnosed in 2018 underwent treatment, according to 2013 Indonesian protocol therapy of ALL.

In the 2018 protocol, the high-risk (HR) group received a total of eight doses Leunase ${ }^{\circledR}$ in the induction phase, given twice a week in 4 consecutive weeks (week 4-7). While in the 2013 protocol, the HR group received a total of nine doses given a week thrice in 3 consecutive weeks (weeks 3-5). The standard-risk (SR) group received a total of six doses and given a week thrice in both protocols, but the administration time was different. The 2018 protocol scheduled Leunase ${ }^{\circledR}$ administration during weeks 5-6 while the 2013 protocol was earlier at weeks 3-4.

The variable data of patient characteristics (age, sex, stratification risk, diagnosis status, nutritional status, and outcome) and allergic reaction characteristics (manifestation and reaction time) were obtained from the investigation. Data collection from the patient's medical record was based on Leunase ${ }^{\circledR}$ administration date that was recorded in the protocol therapy document. Some allergic reaction manifestations were not written down in the medical record. Still, the patient who has an allergic reaction was characterized by the administration route of Leunase ${ }^{\circledR}$ through subcutaneous, intramuscular, and by titration intravenously. The interview was also done to gather information about the manifestation of allergic reactions in allergic patients whose medical record did not have the information about the manifestation of an allergic reaction.

Data analysis was processed using Microsoft ${ }^{\circledR}$ Excel 2016 and IBM $®$ SPSS $®$ version 22. p-value calculation for numerical-categorical data used t-test and categorical-categorical data used Chi-square. The analyzed data were presented in table, percentage and chart to describe patient characteristics and allergic reaction characteristics.

Informed consent was obtained from parents or legal guardians. This study had been approved by the Research Ethical Committee of Universitas Padjadjaran, Bandung, through the letter of approval Number 841/UN6.KEP/EC/2019 and permitted by the Medical Research Ethical Committee of Dr. Hasan Sadikin Hospital, Bandung, with the letter Number LB.02.01/X.2.2.1/12498/2019. This study was also acknowledged and approved by the Department of Child Health Dr. Hasan Sadikin General Hospital, Bandung, Indonesia.

\section{RESULTS}

We studied 69 patients who were diagnosed with ALL from January 1 , 2018-, August 31, 2019, 26 (37.6\%) patients were allergic to Leunase®. The characteristics comparison of allergic versus non-allergic patients is shown in Table 1.

Of 26 patients were allergic to Leunase ${ }^{\circledR}, 35$ allergic reaction manifestations were documented in 22 patients, as shown in Fig. 2.

The allergic manifestations documented in 22 patients were graded based on common terminology criteria for adverse event v3.0, as shown in Fig. 3.

Fig. 4: The reaction time in which the allergic reaction occurs for the $1^{\text {st }}$ time in 26 patients.

The most common reaction time for allergic reaction occurred on the fourth dose of Leunase ${ }^{\circledR}$ administration $(26.9 \%)$, followed by the second dose of Leunase ${ }^{\circledR}$ administration (19.2\%) and first dose as well as third dose (15.4\%).

\section{DISCUSSION}

E. coli-ASP is more prevalent in causing an allergic reaction than other formulations [9]. It is due to its complex structure and heavier molecular weight $[20,21]$. From this study, it was found that the frequency of allergic reaction toward E. coli-ASP is $34.6 \%$. It corresponds with the previous study conducted by Woo et al. that stated allergic reaction to E. coli-ASP ranges from 0 to $45 \%$ [22].

Our study demonstrates various manifestation of an allergic reaction, ranges from mild to severe reactions. It is similar with some previous studies that stated rash, urticaria, flushing, fever, bronchospasm, conjunctival hyperemia, and anaphylaxis are the manifestations of patients who overt allergic reactions [23-26].

In this study, intravenous administration was the first E. coli-ASP exposed to the patients. If the patient showed any sign of allergy, the route of administration was changed to subcutaneous or intramuscular or by titration intravenously. The unavailability of other formulation in Indonesia leads to re-challenge of $E$. coli-ASP in the allergic patient. Twenty-six patients are allergic based on medical record reviews, but only 22 patients had the symptoms written down, and three patients had repeated events. Grades 2 and 3 occurred most often 
Table 1: Characteristics comparison of allergic and non-allergic patient

\begin{tabular}{llll}
\hline Characteristics & $\begin{array}{l}\text { Allergic } \\
\mathbf{n}(\%)\end{array}$ & $\begin{array}{l}\text { Non-allergic } \\
\mathbf{n}(\%)\end{array}$ & p-value \\
\hline $\begin{array}{l}\text { No. of patients (n=69) } \\
\text { Age }\end{array}$ & $26(37.6)$ & $43(62.4)$ & \\
$\quad$ Mean & 6 & 6.06 & 0.945 \\
$\quad$ Median & 4 & 4 & \\
$\quad \begin{array}{l}\text { Range } \\
\text { Standard deviation }\end{array}$ & $1-14$ & $1-17$ & \\
$\begin{array}{l}\text { Gender } \\
\text { Male }\end{array}$ & 4.561 & 4.618 & \\
$\quad$ Female & $15(41.7)$ & $21(53.8)$ & 0.475 \\
Risk at diagnosis & $11(33.3)$ & $22(66.7)$ & \\
$\quad$ High risk & $18(43.9)$ & $23(56.1)$ & 0.197 \\
$\quad$ Standard risk & $8(28.6)$ & $20(71.4)$ & \\
$\begin{array}{l}\text { Patient status at diagnosis } \\
\quad \text { Newly diagnosed }\end{array}$ & $22(48.9)$ & $40(51.1)$ & 0.236 \\
$\quad$ Relapsed & $4(16.7)$ & $3(83.3)$ & \\
Nutritional status & & & \\
$\quad$ Well-nourished & $13(20.2)$ & $23(33.8)$ & \\
$\quad \begin{array}{l}\text { Malnutrition } \\
\text { Overnourished }\end{array}$ & $9(11.6)$ & $16(23.2)$ & \\
\hline
\end{tabular}

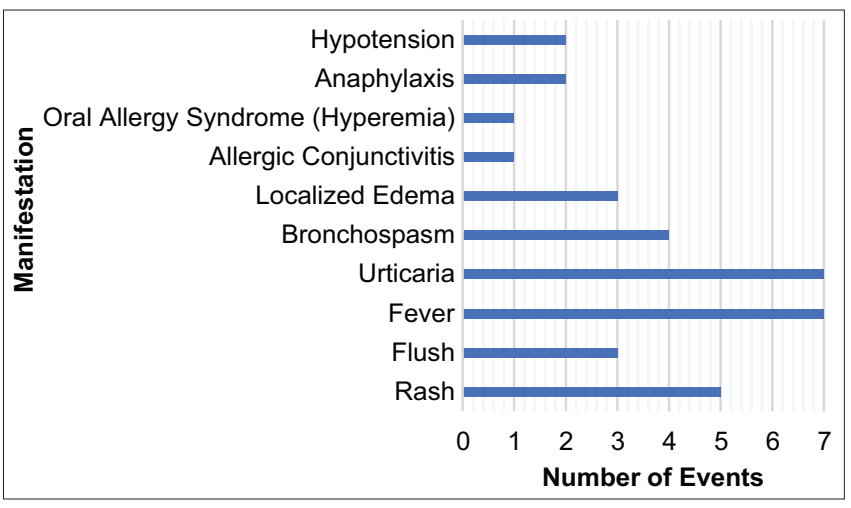

Fig. 2: Manifestation of allergic reaction to Leunase $₫$

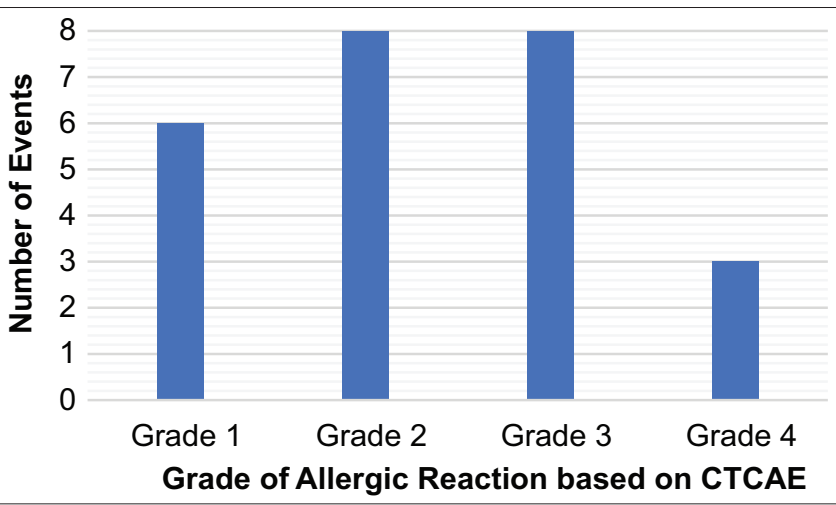

Fig. 3: Grade of allergic reaction based on common terminology criteria for adverse event v3.0

(32\%, respectively), followed by Grade 1 (24\%) and Grade 4 (16\%). On patients who had another allergic reaction after the modification of treatment, the allergic manifestation grades worsen. One patient manifested Grade 1 reaction first and graded four later, and the other two patients had Grade 2 first then later developed to Grades 3 and 4. The first patient died not long after the anaphylactic shock.

Note that, $34.6 \%$ was the incidence of patients that presented the manifestation clinically. The allergic reaction toward asparaginase is

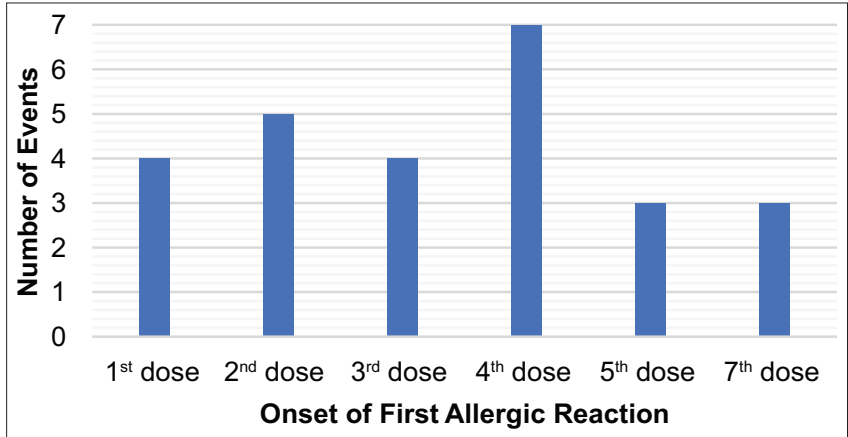

Fig. 4: Reaction time of first allergic reaction

facilitated by the adaptive reaction of theimmune system, the immediate, and antibody-mediated hypersensitivity [27]. Reaction facilitated by a non-antibody mechanism might also provoke manifestation similar to the allergic reaction by activating a complement system. It is called infusion reaction $[24,27]$.

Time of first reaction times was one of the essential signs to differentiate infusion reaction with the allergic reaction, so it needs to be well documented. Allergic reactions rarely manifest at the first occurrence except in a patient with atopy predisposition [16]. Infusion reaction occurs at the first dose of administration, and the manifestation will be improved by the next administration [27]. In our study, four patients (15.4\%) exhibit allergy-alike reaction after the administration of the first dose of Leunase ${ }^{\circledast}$. However, this is not enough evidence to identify this as an infusion reaction since the data of the patient's condition in the next administration were not reported well, and another history of allergy was not investigated.

Furthermore, administration of asparaginase intravenously also induce the increase of ammonia serum [18,23,28]. Hyperammonemia manifests in several ways that are similar to allergic reactions such as rash $[15,20]$. The concurrent use of methotrexate, vincristine, and dexamethasone in the SR patients plus daunorubicin in HR patients also contribute to some extent. A study stated that vincristine and $d$ [18]. However, the number of side effects by asparaginase can alter the pharmacodynamics of other medications. Its hepatotoxicity effect has an impact on drugs metabolized in the liver such as vincristine, methotrexate, and daunorubicin and can become the confounder of an allergic reaction due to asparaginase [29].

In this study, there was no significant difference between the allergic and non-allergic groups in terms of age, gender, risk at diagnosis, patient status at diagnosis, and nutritional status. Risk factors regarding the development of allergic reactions specifically toward E. coli-ASP are not well declared. However, a study by Konstantinidis et al. concluded HR stratified patients, intravenous administration route, and repeated application of the drug after at least 4-week cessation period is a potential risk factor for allergy to L-Asp generally [30]. This dissimilarity is due to the low number of subjects investigated in this study and also retrospective design. Interestingly, a retrospective study done by Padem et al. reviewed that ALL patients from 1993 to 2016 showed an insignificant association between atopy and the likelihood of asparaginase allergy. Only polymorphisms in gene GRIA1 is statistically proven significance as a risk factor for asparaginase allergy [31].

The exhibition of hypersensitivity is more profound in the HR group than the SR group. It accords the previous study from Hasan et al. that demonstrated a high difference in reaction rates in the HR group (35.2\% vs. 2.9\%) [32]. A study also has shown that the HR group is more likely to develop an infusion-related reaction [33]. The median age of patients who were allergic and non-allergic is 4 years old. However, the age range is different. Allergic patient age ranges from 1 year old to 14 years old maximum while the non-allergic maximum 
age is 17 years old. The age distribution is the same across the allergic and non-allergic group. It has been demonstrated in the previous study by Barry et al. that the difference in the incidence of allergic reaction among age groups is not predominant [33]. Male patient accounts for more than a half in the allergic group, similar to a study done by Sitaresmi et al. [4].

This study has limitations; the data collection was done primarily and secondarily. While the primary data collection was done through a phone interview, it was related to information bias that many of the patients have already died, and the guardian might exaggerate the information. Moreover, the secondary data collection is done through investigating the patient's medical record; note that recording of allergic reactions toward medication in Dr. Hasan Sadikin Hospital is still weak. Furthremore, the storage of the patient's medical records mainly done manually, so human error is still high, resulting in the presence of missing data and the need to interview the patient's guardian directly.

Despite these limitations, it is still vital to consider allergy as a reaction to being cautious. The recording of allergy history, E. coli-ASP allergy examination, or premedication needs to be found in treating childhood ALL. Further studies with better design, preferably prospective cohort, may be required to investigate more aspects of allergy biologically and clinically in childhood ALL patients.

\section{CONCLUSION}

Allergic rate to E. coli-ASP at Hasan Sadikin General Hospital is $37.6 \%$ with fever and urticaria as the most frequent manifestations and based on CTCAE the most common is grades 2 and 3 . The reactions emerged mostly after administration of fourth dose E. coli-ASP. Despite the characteristic differences between allergic and non-allergic group, it is not statistically significant.

\section{ACKNOWLEDGMENT}

This study is not supported financially by any funding agencies in public, private, or non-profit sectors.

\section{AUTHOR'S CONTRIBUTION}

1. Nur Melani Sari devised the project, the main conceptual ideas and proof outline, wrote the manuscript

2. Nabilla Osseva: Complied the literature source, worked out almost all the technical detail with data collection, wrote the manuscript

3. Nur Suryawan: Helped in data interpretation and manuscript evaluation.

\section{CONFLICTS OF INTEREST}

The authors declare there are no conflicts of interest.

\section{REFERENCES}

1. American Cancer Society. Global Cancer Facts and Figures. $4^{\text {th }}$ ed. Atlanta: American Cancer Society; 2018. Available from: https://www. cancer.org/research/cancer-facts-statistics/global.html. [Last accessed on 2019 Nov 01].

2. Pui $\mathrm{CH}$, Evans WE. A 50-year journey to cure childhood acute lymphoblastic leukemia. Semin Hematol 2013;50:185-96.

3. Sitaresmi MN, Mostert S, Schook RM, Sutaryo, Veerman AJ. Treatment refusal and abandonment in childhood acute lymphoblastic leukemia in Indonesia: An analysis of causes and consequences. Psychooncology 2010;19:361-7.

4. Sitaresmi MN, Mostert S, Purwanto I, Gundy CM, Sutaryo, Veerman AJ. Chemotherapy-related side effects in childhood acute lymphoblastic leukemia in Indonesia: Parental perceptions. J Pediatr Oncol Nurs 2009;26:198-207.

5. Sari N, Reniarti L, Suryawan N, Susanah S, Wahyudi K. Burden of pediatric cancer treatment: Results of online pediatric cancer registry prototype 1 at a third referral hospital in Indonesia. Althea Med J 2017;4:465. Available from: http://www.journal.fk.unpad.ac.id/index. php/amj/article/view/1204. [Last accessed 2019 Sep 20].

6. Pramila P, Abraham A, Pawar S, Bafna V, Bansal M. To study the therapeutic management, drug related problems and concomitant use of drugsin patients with cancer. Int J Appl Pharm 2017;6:139-44.

7. Cooper SL, Brown PA. Treatment of pediatric acute lymphoblastic leukemia. Pediatr Clin North Am 2015;62:61-73.

8. Indonesian Pediatric Society. Hematology Oncology Working Group. Guideline of National Protocol Acute Lymphoblastic Leukemia 2018, Indonesia; 2018 .

9. Asselin B, Rizzari C. Asparaginase pharmacokinetics and implications of therapeutic drug monitoring. Leuk Lymphoma 2015;56:2273-80.

10. Al-Mashhadani Z, Naser RA, Zalzala MH. The impact of new targeting methods in the cancer therapy. Int J Appl Pharm 2019;11:1-6.

11. Gupta M, Dahiya J, Marwaha, Dureja H. Therapies in cancer treatment: An overview. Int J Pharm Pharm Sci 2015;7:1-9.

12. Hijiya N, Van Der Sluis IM. Asparaginase-associated toxicity in children with acute lymphoblastic leukemia. Leuk Lymphoma 2016;57:748-57.

13. Raetz EA, Salzer WL. Tolerability and efficacy of L-asparaginase therapy in pediatric patients with acute lymphoblastic leukemia. J Pediatr Hematol Oncol 2010;32:554-63.

14. Woo MH, Hak LJ, Storm MC, Sandlund JT, Ribeiro RC, Rivera GK, et al. Hypersensitivity or development of antibodies to asparaginase does not impact treatment outcome of childhood acute lymphoblastic leukemia. J Clin Oncol 2000;18:1525-32.

15. Zalewska-Szewczyk B, Andrzejewski W, Młynarski W, JedrychowskaDańska K, Witas H, Bodalski J. The anti-asparagines antibodies correlate with L-asparagines activity and may affect clinical outcome of childhood acute lymphoblastic leukemia. Leuk Lymphoma 2007;48:931-6.

16. Avramis VI, Tiwari PN. Asparaginase (native ASNase or pegylated ASNase) in the treatment of acute lymphoblastic leukemia. Int $\mathrm{J}$ Nanomedicine 2006;1:241-54.

17. Liu C, Kawedia JD, Cheng C, Pei D, Fernandez CA, Cai X, et al. Clinical utility and implications of asparaginase antibodies in acute lymphoblastic leukemia. Leukemia 2012;26:2303-9.

18. Burke MJ. How to manage asparaginase hypersensitivity in acute lymphoblastic leukemia. Future Oncol 2014;10:2615-27.

19. Ribeiro RC, Gupta S, Antillon FA, Sung L, Howard SC, Fu L, et al. Treatment-related mortality in children with acute lymphoblastic leukemia in Central America. Cancer 2011;117:4788-95.

20. Narta UK, Kanwar SS, Azmi W. Pharmacological and clinical evaluation of L-asparaginase in the treatment of leukemia. Crit Rev Oncol Hematol 2007;61:208-21.

21. Krishna M, Nadler SG. Immunogenicity to biotherapeutics-the role of anti-drug immune complexes. Front Immunol 2016;7:21.

22. Woo MH, Hak LJ, Storm MC, Evans WE, Sandlund JT, Rivera GK, et al. Anti-asparaginase antibodies following $E$. coli asparaginase therapy in pediatric acute lymphoblastic leukemia. Leukemia 1998;12:1527-33.

23. Santos AC, Land MG, Silva NP, Santos KO, Lima-Dellamora ED. Reactions related to asparaginase infusion in a 10-year retrospective cohort. Rev Bras Hematol Hemoter 2017;39:337-42.

24. Burke MJ, Rheingold SR. Differentiating hypersensitivity versus infusion-related reactions in pediatric patients receiving intravenous asparaginase therapy for acute lymphoblastic leukemia. Leuk Lymphoma 2017;58:540-51.

25. Pieters R, Hunger SP, Boos J, Rizzari C, Silverman L, Baruchel A, et al. L-asparaginase treatment in acute lymphoblastic leukemia: A focus on Erwinia asparaginase. Cancer 2011;117:238-49.

26. Bahadir A, Abul MH, Reis PG, Erduran E, Orhan F. Adverse skin reactions caused by L-asparaginase: Allergy or infection. Asthma Allergy Immunol 2015;13:130-3. Available from: http://www.aai.org. tr/index.php/aai/article/view/70/7. [Last accessed on 2019 Dec 05]

27. Asselin B. Immunology of infusion reactions in the treatment of patients with acute lymphoblastic leukemia. Future Oncol 2016;12:1609-21.

28. Nussbaum V, Lubcke N, Findlay R. Hyperammonemia secondary to asparaginase: A case series. J Oncol Pharm Pract 2016;22:161-4.

29. Gerson SL, Caimi PF, William BM, Creger RJ. Pharmacology and molecular mechanisms of antineoplastic agents for hematologic malignancies. In: Hoffman R, Benz EJ Jr., Silberstein LE, Heslop H, Anastasi J, Weitz J. Hematology: Basic Principles and Practice. $7^{\text {th }}$ ed. Philadelphia, PA: Elsevier; 2018. p. 890-910.

30. Konstantinidis N, Kolarovic J, Kacanski N, Vijatov-Djuric G, Konstantinidis G. Allergic complications of L-asparaginase therapy in children with acute lymphoblastic leukemia. Srp Arh Celok Lek 2011;139(11-12):749-52

31. Rajić V, Debeljak M, Goričar K, Jazbec J. Polymorphisms in GRIA1 gene are a risk factor for asparaginase hypersensitivity during the 
treatment of childhood acute lymphoblastic leukemia. Leuk Lymphoma 2015;56:3103-8

32. Hasan H, Shaikh OM, Rassekh SR, Howard AF, Goddard K. Comparison of hypersensitivity rates to intravenous and intramuscular PEGasparaginase in children with acute lymphoblastic leukemia: A meta- analysis and systematic review. Pediatr Blood Cancer 2017;64:81-8.

33. Barry E, DeAngelo DJ, Neuberg D, Stevenson K, Loh ML, Asselin BL, et al. Favorable outcome for adolescents with acute lymphoblastic leukemia treated on Dana-Farber cancer institute acute lymphoblastic leukemia consortium protocols. J Clin Oncol 2007;25:813-9. 